\title{
The Impact of Self-assessment of EFL Learners' Tolerance of Ambiguity
}

\author{
Zahra Jafari $^{1}$, Samira Yavari $^{2}$, Moein Shokri ${ }^{3}$ \\ ${ }^{1}$ Department of English Language, Harsin Branch, Islamic Azad University, Kermanshah, Iran \\ ${ }^{2}$ English Department-Kermanshah Jihad Daneshgahi Institute of Higher Education, Kermanshah, Iran \\ ${ }^{3}$ Department of English Language, Kermanshah Branch, Islamic Azad University, Kemanshah, Iran \\ Email address: \\ Zjafari44@gmail.com (Z. Jafari), Samirayavari233@gmail.com (S. Yavari), Shokri_moin@yahoo.com (M. Shokri)
}

\section{To cite this article:}

Zahra Jafari, Samira Yavari, Moein Shokri. The Impact of Self-assessment of EFL Learners' Tolerance of Ambiguity. International Journal of Language and Linguistics. Vol. 3, No. 4, 2015, pp. 271-274. doi: 10.11648/j.ij11.20150304.22

\begin{abstract}
Tolerance of ambiguity has been an important focus of educational practices and research for more than three decades. The present paper investigated the possibility that there might be an impact of self-assessment on Iranian intermediate EFL learners' tolerance of ambiguity and language proficiency. Therefore, two groups each with 20 EFL intermediate learners served as the experimental and control groups. In the experimental group, self-assessment was practiced. While the participants of control group, just received traditional evaluation. Ely (1995) Ambiguity Tolerance Questionnaire (ATQ) was administered as the measure of learners' tolerance of ambiguity. The results of the study indicate that learners' tolerance of ambiguity increases as the effect of self-assessment. Self-assessment can also affect the learners' proficiency in general.
\end{abstract}

Keywords: Tolerance of Ambiguity, Self-assessment, Language Proficiency

\section{Introduction}

Debate about the value of Ambiguity Tolerance (AT) on language learning has been prominent in recent years. The educational background of learners has been identified as a subject variable that might have an effect on the extent to which some students benefit from a high tolerance of ambiguity. According to Kamran and Maftoon, (2012) "Language learning is a matter of having the ability to deal with unknown and even vague features of a new language and the one who owns the ability of such adaptation and tolerance is predicted to become a successful language learner" (p.1). Rubin (1975) characterizes the good language learner as the one who is often not inhibited and who is willing to make mistakes in order to learn and to communicate, and who is willing to live with a certain amount of vagueness.

Consequently one of the main challenges that educational system faced is how to help EFL learners improve their ambiguity tolerance in language learning. In Asian context, EFL learners are passive learners and almost there is no opportunity for them to enhance their tolerance of ambiguity. As Harris (1997) points out that, "one of the fundamental elements of self-directed language learning is the opportunity given to learners to assess their own progress and thus help them to focus on their own learning" (p.12).Accordingly, the current study makes such an attempt to find a way to enhance AT and its impact in language learning. Therefore in the present study self-assessment was considered as a treatment that may has effect on learners' tolerance of ambiguity and also language proficiency.

\section{Research Questions and Hypotheses}

1. Does self-assessment improve learners' tolerance of ambiguity?

2. Does self-assessment improve learners' English language proficiency?

\section{Review of the Related Literature}

During the last decades, the role played by tolerance of ambiguity in language acquisition has been a highly controversial issue. Defining ambiguity tolerance is complex since many nuances are interwoven in the term. However, intolerant learners may tend to avoid or give up when encountering ambiguous situations. In the attempt to describe tolerance of ambiguity, a double task is faced to: assign what tolerance is and to interpret the meaning of ambiguity. 
According to Budner (1962) ambiguous situations can be three different types, new situations, complex situations, and contradictory situations. Norton (1975) summarizes causes of ambiguity as: multiple meanings, vagueness, incompleteness, or fragmentation, a probability, unstructured, lack of information, uncertainty, inconsistencies and contradictions, and unclear. Ely (1989) defines tolerance of ambiguity as the acceptance of uncertainties.

McLain (1993: 184) postulates that tolerance suggests 'begrudging acceptance' whereas 'intolerance suggests rejection' and adds that tolerance extends along a continuum from rejection to attraction'.

It is suggested that moderate levels of tolerance of ambiguity are recommended for optimum results in language learning. Since high tolerance may cause cognitive passivity and low tolerance may impede language learning, midpoint tolerance seems to be satisfactory. (Ely 1995, Ehrman 1996).

Many of the ambiguous situations are also common in language learning and it happens in the classroom with a group of students (Ely, 1995) or individually when people engage in self-instructed language study (White, 1999).

According to Chappelle and Roberts (1986) ambiguity tolerance is "a person's ability to function rationally and calmly in a situation in which interpretation of all stimuli is not clear" (p.30).

McLain (1993) supposed that people consider ambiguous stimuli as probable sources of hazard because these stimuli are new, intricate or inexplicable, they exhibit intolerance of ambiguity, then they become unwilling to accept new stimuli, analyze complicated data or deal with cases that contain opposing elements. Or that is, people with ambiguity tolerant are willing to deal with new; complex and inexplicable situations are more receptive to change, more willing to take risks.

The level of AT may also influence the use of certain language learning strategies. Ehrman and Oxford (1990) found that learners with instinctive types of personalities who have relatively higher levels of AT reported that they often guessed from context whereas sensing types of personalities with lower AT reported that they disliked having to guess from context.

Ellis (1994) provided a description which may also have implications for the effect caused by the use of the learner's first language in second language studies. Ellis described tolerance of ambiguity as a dimension of second language learning which "entails an ability to deal with ambiguous new stimuli without frustration and without appeals to authority [e.g., the first language]. It allows for indeterminate rather than rigid categorization" (p. 518)

As Brown (2000) said ambiguity tolerance allude to the extent to which you are cognitively eager to tolerate ideas and opinions that contradict to your own belief system or structure of awareness. It is favorable to find source of ambiguity tolerance, explain the role it plays and determine the way through which it can effect learners in a language learning situation for understanding the notion of ambiguity tolerance better, and its relation to language learning context.
Brown (2000) considered ambiguity tolerance as potentially important contributors to successful achievements as one of those styles that have appeared in second language research.

Kazamina (1999) concluded that ambiguity is indicated by "novelty, complexity, insolubility and lack of structure."(p. 69). Jonassen and Grabowski (1993) supposed that tolerant individuals should perform well in new and complicated learning situations. However, intolerant learners may tend to keep away from or give up when encountering ambiguous situations.

Reises (1985) found that students who show that tolerance of ambiguity is significant for them consider themselves as good language learners. She came to an end that one who among other things moderately comfortable with ambiguity is a good language learner.

Ambiguity in language learning can cause nervousness (Ehrman, 1999), which may generate "a degree of apprehension and frustration which may be deleterious to progress" (White, 1999, p.451). Ely (1995) specifies three circumstances where tolerance of ambiguity has a negative impression on language learning:

1: learning individual linguistic elements (phonological, morphological, syntactic, semantic, etc).

2: performing language learning skills

3: adopting those skills as enduring strategies

Given the above mentioned issues on the purpose and significance of this study, the study sought to find a way to improve AT in Iranian EFL learners. Different language teaching methods and instruments have been introduced in order to develop learners' tolerance of ambiguity in language learning, one of these ways might be self-assessment.

As Gardner (2000) pointed out self-assessments provide learners personalized feedback on the effectiveness of their learning strategies, specific learning methods and learning materials. Learners can use this feedback to evaluate their approach to language learning. He also added that this is part of learners' reflection about learning, so in selecting, administering and considering the results of self-assessments learners must necessarily reflect on their goals, strategies and achievements.

Smith (1997) highlights the importance of self-assessment and argues by using it students become deeply self-motivated and independent learners. They become honest with themselves when goal setting. Therefore, as mentioned above, self-assessment techniques can give a lot of valuable information to be served in learning and teaching process. In the same vein, in order to show the importance of selfassessment in language learning, Cresswell (2000) asserted that such techniques help to enhance students' awareness of self-monitoring and this awareness gives them positive feedback about their own learning. Accordingly The present study is an attempt to demonstrate the effectiveness of selfassessment on EFL learners' ambiguity tolerance in Iranian context which the traditional attitude hold by teachers and learners towards their very own roles seem to be barrier to self-access and independency on the part of the language learner, so the research aims at finding out whether self- 
access can affect learners ambiguity tolerance on one hand and language proficiency on the other.

\section{Methodology}

The participants were 40 both male and female adult English learners all intermediate studying English in 2 classes. In one, self-assessment was practiced and the other class served as the control group. None of the candidates knew that they were part of a research project so there was a kind of randomization to ensure the validity of the results. To identify the degree of participants' tolerance of ambiguity, the Persian version of Ambiguity Tolerance Questionnaire (ATQ) developed by Ely (1995) was used. The students' proficiency was measured using Oxford English Language Placement Test.

ATQ was administered in class prior to the study as a pretest and after the implementation period at the end of the sixteenth week as a post-test.

The questionnaire includes 12 items and the responses are in Likert-scale format with a set of four responses including strongly agree, agree, disagree, and strongly disagree. The reliability of the questioner in piloting phase was computed through Cronbach alpha at 0.81 . As indicated in table 1 , there is no significant difference between the groups as pre-test in terms of ambiguity tolerance. $(.31>.05)$

Table 1. statistics for ATQ as a pretest.

\begin{tabular}{lllllll}
\hline & N & Mean & Std. Deviation & t & df & $\begin{array}{l}\text { Sig (2- } \\
\text { tailed) }\end{array}$ \\
\hline CNT & 20 & 19.05 & 3.54 & 1.02 & 38 & 0.31 \\
EXP & 20 & 18.11 & 3.25 & & & \\
\hline
\end{tabular}

Oxford English Language Placement Test( OELPT) was used to find any significant difference between the classes which have practiced self-assessment different and the control one.

First 53 intermediate students were selected. To make sure that the participants were at the same level of proficiency, intermediate level, the OELPT was administrated. Those participants who have 21-30 correct answers out of 50 items were accepted to participate in this study as intermediate learners.

Table 2. statistics for OELPT as the pre-test.

\begin{tabular}{lllllll}
\hline & N & Mean & Std. Deviation & t & df & $\begin{array}{l}\text { Sig (2- } \\
\text { tailed) }\end{array}$ \\
\hline CNT & 20 & 22.25 & 1.01 & 1.35 & 38 & \\
EXP & 20 & 21.75 & 1.29 & & & .182 \\
\hline
\end{tabular}

The participants with scores below 21 and above 30 were excluded from the study. Thus, as demonstrated by Table 2 , forty of participants were selected from the main analysis.

The participants in the experimental group were required to self-assessment every week, which included selfassessment checklists of the learners on their learning experiences and performance in class and their experiences in the institute they were learning as a whole. The duration of the learning practice was 16 weeks. Self-assessment checklists were collected by the instructor every week. Selfassessment checklists were checked by the instructor in order to make sure the participants were following the steps they had to consider in the process self-assessment. After 16 weeks, self-assessment practice by the participants in the experimental group, both experimental and control groups were invited to mark the ATQ and OELPT once more as the post-test of the study. The scores of the pre and postquestionnaires were analyzed based on the following procedure.

Table 3. statistics for ATQ as a post-test.

\begin{tabular}{l|llllll}
\hline & N & Mean & Std. Deviation & t & df & $\begin{array}{l}\text { Sig (2- } \\
\text { tailed) }\end{array}$ \\
\hline CNT & 20 & 20.80 & 3.27 & 8.01 & 38 & .000 \\
EXP & 20 & 29.30 & 3.41 & & & \\
\hline
\end{tabular}

Based on independent sample t-test results in table 3 for ATQ as a post-test, the mean score in the control group is 20.80 and in experimental group score is 29.30 , differences between mean scores of the two groups were found to be significant $(\mathrm{t}(38)=8.01, \mathrm{p}<0.05)$. The sig $(.000<.05)$ depicts that students' tolerance of ambiguity increased as the effect of self-assessment.

Since the study was an investigation of the impact of selfassessment both on learner tolerance of ambiguity and general proficiency, the same version of OELPT was also used as the post-test to realize whether self-assessment has any impact on the proficiency of language learners.

Table 4. statistics for OELPT as the posttest.

\begin{tabular}{lllllll}
\hline & N & Mean & Std. Deviation & t & df & $\begin{array}{c}\text { Sig (2- } \\
\text { tailed) }\end{array}$ \\
\hline CNT & 20 & 23.80 & 3.27 & 8.03 & 38 & .000 \\
EXP & 20 & 29.30 & 3.41 & & & \\
\hline
\end{tabular}

Based on what is indicated in table.4 in which sig is less than $\mathrm{p}$-value $(.000<.05)$. Therefore it can be concluded that self-assessment has positive impacts on language proficiency.

\section{Conclusion}

Within a few years, numerous efforts have been made based on learners' ambiguity tolerance and some have suggested ways to improve EFL learners' tolerance of ambiguity. However in teaching, little or no attempt has been made concerning the impact of self-assessment in Asian context especially in Iran. According to Campbell, Dewall, Roth, and Stevens (1998) self-assessments "provided students with a greater sense of ownership of their work, a more enthusiastic approach to learning, and the increased use of higher-order thinking" (p. 1). The present study therefore, examined the impact of self-assessment on learner ambiguity tolerance in Iranian context, by considering this hypothesis "self-assessment does not improve Iranian EFL learners' tolerance of ambiguity ".

As Ehrman (1996) asserts that, 'effective language 
learning is very much a process of reinterpreting one's view of reality using alternative perspectives' (p. 177). Ely (1989) mentioned that in language learning ambiguity is appeared as uncertainty. He clarified this concept in this way that language learning is 'fraught with uncertainty' and examples that causes uncertainty in fact are those learners who seldom know the precise meaning of a new lexical item or feel that they have entirely comprehended the chronological reference of a grammatical tense or have pronounce a sound with total accuracy. By using self-assessment techniques, learners can receive direct feedback to identify their language ability and to select suitable learning strategies.

Therefore the present research attempts to consider a way to improve learner tolerance of ambiguity in EFL context. Self-assessment was practiced as a way to develop learners' ambiguity tolerance. The results indicate that practicing selfassessment can enhance learner ambiguity tolerance. It also helped the learners to improve their proficiency.

The findings of present paper afford practical implications and suggestions for EFL learners, teachers, educators and administrators to improve qualities of material, syllabus design and learning processes by improving AT among EFL students. Learners and teachers are recommended to develop and integrate the abilities related to AT in and out of the classroom context through different procedures of selfassessments in writing such as self-assessment check list or other self-assessment techniques such as concept mapping, portfolio and journal writing. The use of these techniques not only may result in the development of language proficiency but also may enhance AT in EFL learning. Consequently, if learners are explicitly or implicitly taught some techniques to enhance their AT they would be able to overcome learnings' barrier in new situations like foreign language learning which seems to be a demanding task for them

\section{References}

[1] Brown, H. D. (2000). Principles of language learning and teaching (4th ed.). New York: Pearson Education.

[2] Brown, H. D. (2001). Teaching by principles: An interactive approach to language Pedagogy. New York: Longman.

[3] Budner J. (1962). Tolerance of ambiguity as a personality variable. Journal of Personality. 30, 29-40.

[4] Campbell, D., DeWall, L., Roth, T., \& Stevens, S. (1998). Improving student depth of understanding through the use of alternative assessment. Unpublished Doctoral Dissertation, Cambridge, Cambridge university press.
[5] Chapelle, C., \& Roberts, C. (1986). Ambiguity tolerance and field independence as predictors in English as a second language. Language Learning , 36 (1), 27-45.

[6] Ellis, R. (1994). The study of second language acquisition. New York: Oxford University press.

[7] Ely, C. (1989). Tolerance of ambiguity and use of second language strategies. Foreign Language Annals, 22, 437-445.

[8] Ely, C. M. (1995). Tolerance of ambiguity and the teaching of ESL. Boston: Heinle \& Heinle.

[9] Ehrman, M. E. (1996).understanding second language learning difficulties. Thousand Oaks: Sage Publications.

[10] Ehrman, M. (1999). Ego boundaries and tolerance of ambiguity in second language learning. In Arnold, J. (Ed.).affect in language learning. Cambridge:Cambridge University Press.

[11] Ehrman, M., \& Oxford, R. 1990. "Adult Language Learning Styles and Strategies in an Intensive Training Setting." Modern Language Journal 74.3: 311-327.

[12] Gardner, D. (2000). Self-assessment for autonomous language learners. Links \& Letters, 7.

[13] Harris, M. (1997). Self-assessment on language learning in formal setting. ELT Journal, 51(1), 12-14.

[14] Jonassen, D. H., \& Grabowski, B. L. (1993) .Handbook of individual differences, learning and instruction Hillsdale, NJ: Lawrence Earlbaum Associates.

[15] Kamran, S. K., \& Maftoon, P. (2012). An analysis of the associations between ambiguity tolerance and EFL reading strategy awareness. English Language Teaching, 5(3), p188.

[16] Kazamia, V. (1999). "How Tolerant are Greek EFL Learners of Foreign Language Ambiguities." Foreign Language Annals 22: 437-445.

[17] McLain, D. L. (1993).The MSTAT-I: A new measure of an individual's tolerance for ambiguity. Educational and Psychological Measurement, 53,183 189.

[18] Norton, R.W. (1975). Measurement of ambiguity tolerance. Journal of Personality Assessment, 39, 607-619.

[19] Reiss, M. (1985)."The good language learner:Another look".canadian Modern Language Review 40, 257-266.

[20] Rubin, J. (1975). What the" good language learner" can teach us. TESOL quarterly, 41-51.

[21] Smith, C. (1997). Student self-assessment at St. Bernadette's primary school. Primary Educator, 3(4), 7-14.

[22] White, C. (1999). Expectations and emergent beliefs of selfinstructed language learners. System, 27, 443-457. 